\title{
Relationship of Insulin Dose, A1c Lowering, and Weight in Type 2 Diabetes: Comparing Insulin Glargine and Insulin Detemir
}

\author{
George Dailey, M.D., ${ }^{1}$ Karim Admane, M.D., ${ }^{2}$ Florence Mercier, M.Sc., ${ }^{3}$ and David Owens, M.D. ${ }^{4}$
}

\begin{abstract} (51.5 vs. $38.8 \mathrm{U} /$ day).

\section{Introduction}

I NSULIN THERAPY IS THE MOST EFFECTIVE method of reducing blood glucose levels in patients with type 2 diabetes mellitus (T2DM). However, it is also well recognized that improvements in glycemic control can be associated with an increase in body weight. One study demonstrated that each $1 \%$ absolute reduction in hemoglobin A1c (A1c) achieved with neutral protamine Hagedorn (NPH) insulin was associated with an increase in body weight of $2 \mathrm{~kg}$ in patients with T2DM. ${ }^{1}$ Individuals needing the higher doses of insulin gain the most weight. ${ }^{2,3}$ Consequently, patients with the poorest levels of glycemic control are at greatest risk of increasing body weight when insulin is introduced.
\end{abstract}

Background: A pooled analysis of randomized controlled trials of individuals with type 2 diabetes mellitus (T2DM) was conducted to compare dosing and impact of two basal insulin analogs, insulin glargine (glargine) and insulin detemir (detemir), on weight and hemoglobin A1c (A1c).

Methods: Twenty-two studies of at least 20 weeks in duration in individuals with T2DM initiating glargine/ detemir were included. Results were combined using a weighted-average method and a bivariate random effect model. Outcomes included changes in weight, A1c, and insulin dose from study start to end.

Results: One study was head-to-head comparison of glargine and detemir. Detemir (four studies) was administered once or twice daily, with $50 \%$ starting on detemir once daily but needing therapy intensification. Glargine was used once daily in all 18 studies. The Egger test was borderline significant for change in weight over the course of the treatment for glargine $(0.29 ; 90 \%$ confidence interval $[\mathrm{CI}]-0.01,0.58)$, and heterogeneity was not observed for detemir $(-0.18 ; 90 \% \mathrm{CI}-0.59,0.23)$. Heterogeneity was observed for change in A1c over the course of the treatment (glargine, $-1.19,90 \% \mathrm{CI}-1.74,-0.63$; detemir, $-2.65,90 \% \mathrm{CI}-4.86,-0.45$ ). Nonheterogeneity for change in A1c over the course of the treatment was achieved by excluding five studies for glargine and one study for detemir; however, all studies were included in subsequent analyses. In the unadjusted model, glargine and detemir showed similar results for mean A1c change $(-1.4 \%$ vs. $-1.4 \%)$, weight gain $(2.5 \mathrm{vs} .1 .7 \mathrm{~kg})$, and weight/A1c (1.8 vs. $1.2 \mathrm{~kg} / \%)$. A significantly higher detemir dose was needed to achieve the same A1c change

Conclusions: Although absolute weight gain was higher with glargine versus detemir, weight gain per A1c change was similar. A higher detemir dose was required to achieve a similar A1c reduction.

The negative impact of weight gain on individuals with T2DM is both physiologically and psychologically. ${ }^{4-6}$ The fear of weight gain is recognized as a psychological barrier that can lead to a reluctance to initiate and titrate insulin appropriately, when oral antidiabetes agents (OADs) fail to maintain A1c targets below $7 \% .{ }^{7-10}$ In addition, obesity predicts a poor response to any type of insulin therapy, especially if insufficient doses of insulin are used. ${ }^{11,12}$ Managing weight gain is, therefore, an important consideration when initiating insulin therapy for the first time. Changes to lifestyle and diet can help to offset increases in weight due to treatment, and the concomitant use of a weight neutral treatment, such as metformin, can also be considered.

In the absence of an adequate and sustained response to lifestyle changes and OADs, basal insulin analogs, such as

\footnotetext{
${ }^{1}$ Scripps Clinic Torrey Pines, San Diego, California.

${ }^{2}$ sanofi-aventis, Paris, France.

${ }^{3}$ Stat Process, Port-Mort, France.

${ }^{4}$ Diabetes Research Unit, Cardiff University, University Hospital Llandough, Penarth, United Kingdom.
} 
insulin glargine (glargine) and insulin detemir (detemir), offer a simple approach to the introduction of insulin. Once-daily dosing with glargine and once- or twice-daily dosing with detemir are associated with further improvement in glycemic control and a lower risk of hypoglycemia versus NPH insulin. ${ }^{13,14}$ Some studies in type 1 diabetes mellitus and T2DM have suggested that treatment with detemir results in less weight gain compared with either glargine ${ }^{2,15}$ or NPH. ${ }^{14,16-24}$ The differences, however, are relatively small in magnitude $(<2 \mathrm{~kg})$.

The aim of this review was to conduct a literature search to compare studies involving individuals with T2DM, with or without prior insulin use, and the impact of glargine and detemir treatment on weight gain in relationship to reductions in A1c. An analysis to determine the relationship between reductions in $\mathrm{A} 1 \mathrm{c}$ and final insulin dose was also performed.

\section{Subjects and Methods}

\section{Search terms}

The aim of the literature search was to identify randomized controlled trials that evaluated glargine or detemir in persons with T2DM. A search of the MEDLINE database was conducted from January 1, 2000 to December 31, 2008 using the following terms: "glargine," "insulin glargine," "LANTUS ${ }^{\circledR}$," "HOE901," "detemir," "insulin detemir," "levemir," "NN304," and "Type 2 diabetes."

\section{Study selection}

Randomized, controlled trials were included if they had an active comparator, the treatment duration was at least 20 weeks, and reported clinical outcomes included A1c, change in weight or body mass index, insulin dose, and data on whether concomitant treatment with OADs was used. If numerous published articles existed on a trial, the article that included the most data was chosen; other related publications were omitted.

\section{Outcomes}

The outcomes analyzed included changes in weight, A1c, and insulin dose from start to end of study and relationship between reductions in A1c and changes in weight or insulin dose at the end of the study.

\section{Statistical analysis}

A statistical analysis was carried out involving all studies in order to assess the change in weight and final insulin dose, adjusted per $1 \%$ A1c reduction.

Importantly, testing for heterogeneity of articles, i.e., that the results of the studies were similar enough that a combined estimate would be a meaningful description, was performed in relationship to A1c and weight using an Egger test and inverted funnel plots.

A weighted average method was used to combine the results of the studies using a bivariate random effects model. The PROC NLMIXED (SAS version 9.2, SAS Institute, Cary, NC) statistical procedure was used. A first model was built to estimate change in A1c and weight, and a second model was constructed with the ratio between the change in weight and
A1c to estimate the final insulin dose with the A1c reduction and the ratio between the final dose and the A1c change. This method allows the retention of the maximum amount of data for the analysis, i.e., the change in A1c when the changes of weight over the course of treatment are missing.

When SDs were unknown, the maximum SDs observed in other studies were substituted. This is a conservative method, in that as a study with unknown variance and a small number of subjects will have a small weighting in the analysis, with a bigger weight given to studies with a large number of subjects. This again ensures the maximum amount of data can be utilized for the analysis. For the weight analysis, body mass index was used instead for the baseline value because it was more systematically reported in studies.

A secondary analysis of individuals without history of insulin use was performed using the above methodology.

\section{Results}

\section{Summary of analyzed studies}

A total of 22 studies were identified using our search criteria: 18 glargine ${ }^{2,25-41}$ and three detemir ${ }^{14,42,43}$ trials, with one study $^{2}$ involving both glargine and detemir data. Glargine was prescribed once daily in all 18 studies. Detemir was given twice daily in one study ${ }^{14}$ and once daily in one study, ${ }^{42}$ and individuals were started on once-daily dosing and progressed to twice-daily dosing as required in two studies. ${ }^{2,43}$

Study designs and baseline characteristics of the individuals enrolled in the glargine and detemir trials are presented in Table 1. In total, 4,091 and 1,086 glargine- and detemirtreated individuals, respectively, were included in the analysis. Individuals were non-insulin-treated subjects except in one study, ${ }^{41}$ where participants who were receiving a rapidacting insulin analog plus NPH either continued their treatment or had the NPH replaced with glargine. The treatment period was 24 weeks or more in all but one study for detemir, ${ }^{42}$ where the study duration was 20 weeks. Basal insulin was given in combination with OADs in all but one study with glargine. ${ }^{32}$ Table 2 summarizes the change in A1c, weight, and insulin dose at the end of the study period for each of the glargine and detemir trials.

\section{Glycemic control}

Baseline A1c ranged from $8.1 \%$ to $9.8 \%$ and from $8.6 \%$ to $9.1 \%$ in the glargine and detemir studies, respectively (Table 1). Change in A1c from baseline to end point ranged from -0.30 to $-2.36 \%$ for the glargine studies and from -0.8 to $-1.8 \%$ for the detemir studies (mean change, $1.4 \%$ for both insulins) (Table 2).

\section{Change in weight}

The baseline body mass index ranged from 24.8 to 34.6 $\mathrm{kg} / \mathrm{m}^{2}$ in the glargine studies and 28.9 to $30.6 \mathrm{~kg} / \mathrm{m}^{2}$ in the detemir studies (Table 1). The initiation of glargine or detemir was associated in all studies with increases in weight (Table 2). In individuals taking glargine, weight gain from baseline to the end of the study ranged from +1.4 to $+3.9 \mathrm{~kg}$ compared with +0.7 to $+3.0 \mathrm{~kg}$ in the detemir studies. Of note is that no difference in weight gain was observed between morning and evening glargine administration. ${ }^{27,37}$ Weight gain was higher in individuals receiving detemir twice daily compared with 


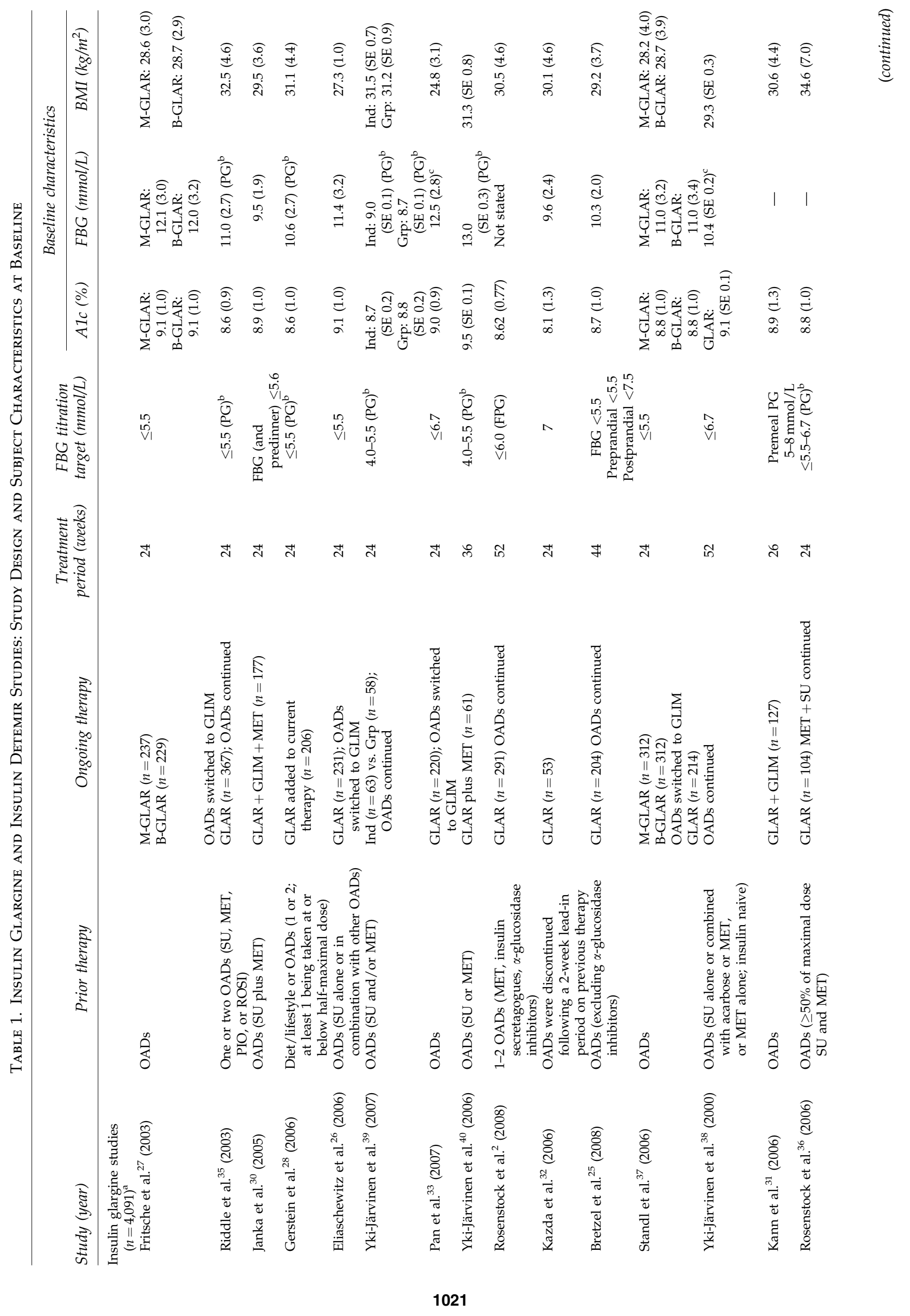




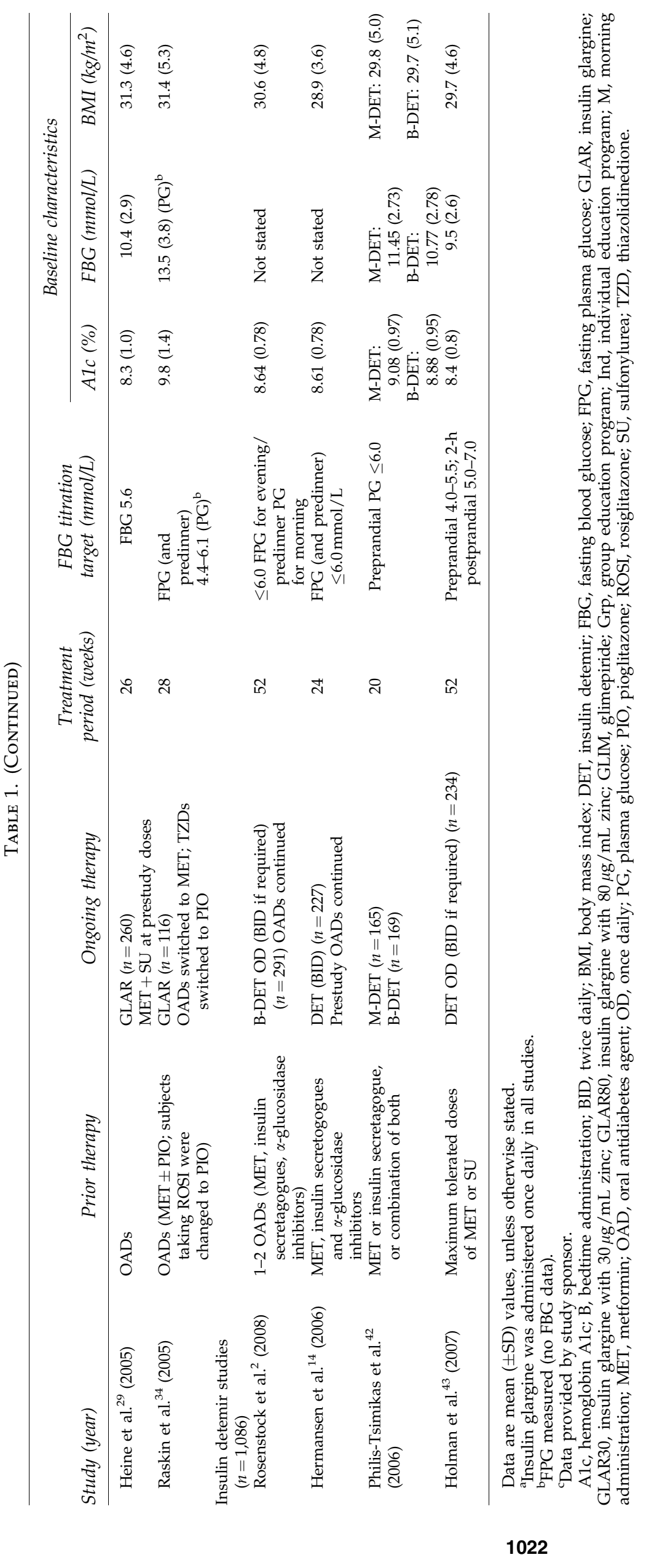




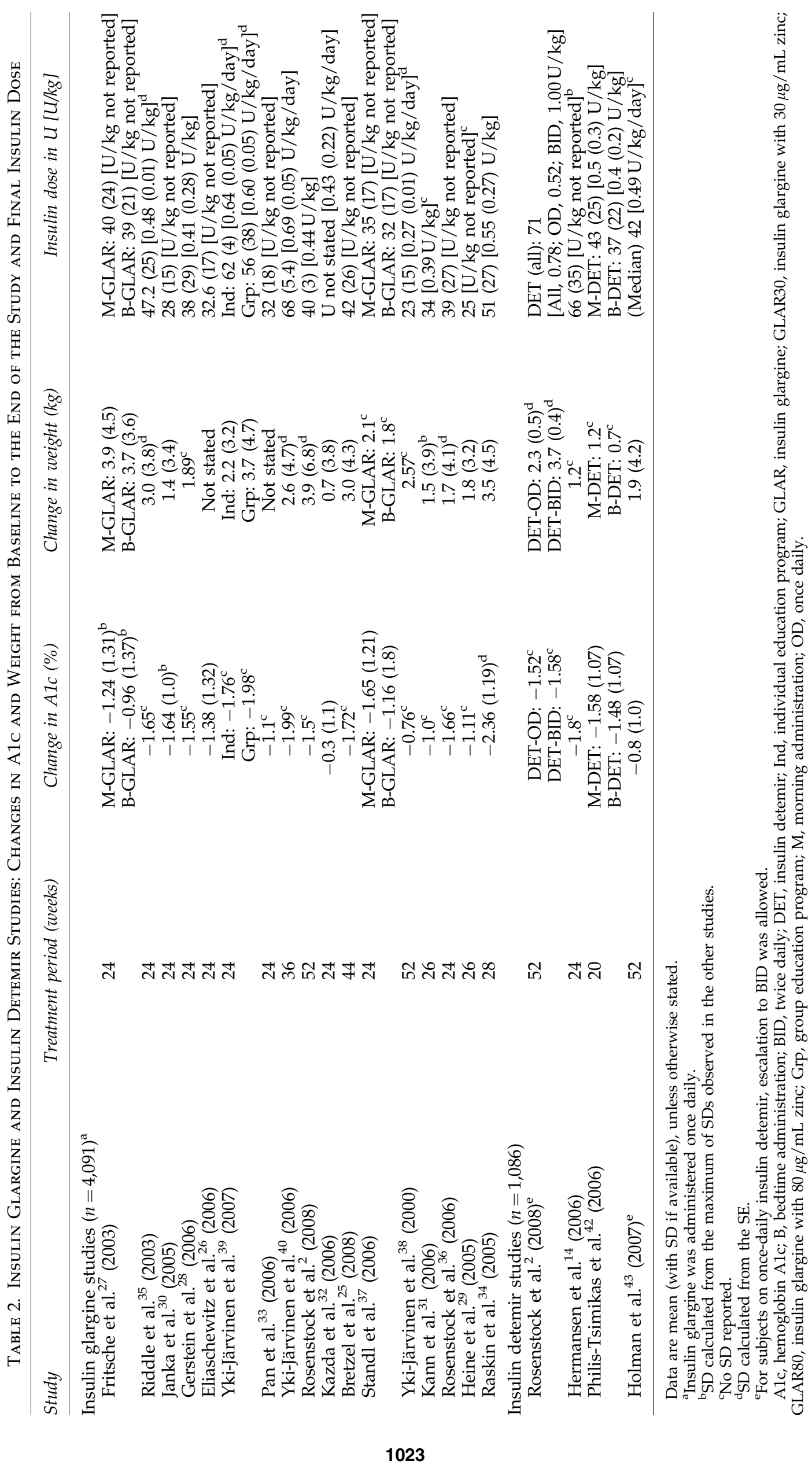


those receiving once-daily detemir. In the single detemir study providing results stratified by both once- or twice-daily dosing, the insulin dose in the twice-daily group was almost double that in the once-daily group, with $55 \%$ of participants requiring twice-daily dosing. ${ }^{2}$ However, the change in A1c in the twice-daily group was just $0.04 \%$ more than that in the once-daily group (A1c change, $-1.58 \%$ vs. $-1.52 \%$ ), whereas weight gain was $61 \%$ higher in the twice-daily group (3.7 vs. $2.3 \mathrm{~kg}$; Table 2). ${ }^{2}$

\section{Change in insulin dose}

Insulin dose at end point ranged from 23 to $68 \mathrm{U}$ in the glargine studies and from 37 to $71 \mathrm{U}$ in the detemir studies (see Supplementary Appendix 1 at www.liebertonline.com/ dia). In the two once-daily detemir studies, which allowed individuals to receive an additional daily injection if target blood glucose was not reached, $34 \%$ and $55 \%$, respectively, of the subjects required twice-daily detemir at the end of the study. ${ }^{2,43}$ Considering all four studies of detemir, $42 \%$ of subjects used detemir twice daily at the end of the studies, which was associated with higher daily insulin and as evident in the one detemir study that reported results stratified by once- or twice-daily dosing ${ }^{2}$ (Table 2).

\section{Model Results: Weight Gain and Insulin Dose Adjusted for A1c Reduction}

Of note is that $13,2,14,25,28,29,31,33,35,36,38-41$ eight, ${ }^{14,26,28,33,37,41,42}$ and five ${ }^{2,29,31,32,43}$ studies had missing SDs for A1c, weight, and insulin dose, respectively, and therefore the maximum SDs from other equivalent studies included in the pooled analyses were used instead.

Results of the Egger test were borderline significant in terms of the change in weight over the course of the treatment for glargine $(0.29 ; 90 \%$ confidence interval [CI] 0.01, 0.58). If five studies were excluded, ${ }^{32,39-41,44}$ the Egger test was no longer significant $(0.03 ; 90 \% \mathrm{CI}-0.34,0.39)$. The Egger test was not significant in terms of the change in weight over the course of the treatment for detemir $(-0.18 ; 90 \%$ CI -0.59 , $0.23)$.

However, heterogeneity was observed for change in A1c over the course of the study for glargine $(-1.19 ; 90 \% \mathrm{CI}-1.74$, $-0.63)$ with the exclusion of two studies ${ }^{32,41}$ and detemir $(-2.65 ; 90 \% \mathrm{CI}-4.86,-0.45)$. For the change in A1c analysis, involving the glargine studies, the absence of heterogeneity was obtained after excluding five studies ${ }^{32,34,39-41}(-0.18 ; 90 \%$ CI $-0.85,0.49)$. For the detemir studies, if the study by Holman et al. ${ }^{43}$ was excluded, the Egger test was no longer significant $(-0.68 ; 90 \% \mathrm{CI}-5.86,4.50)$.

For the purpose of this pooled analysis, as the Egger test demonstrated limited heterogeneity in weight gain among the studies, the absence of excessive variation between all identified studies validates the pooling of the data. This ensured that studies with a large number of patients would not be excluded and that the impact of covariates could be studied.

\section{Change in weight per $1 \%$ A1c reduction}

For the unadjusted model (inclusion of all studies and without adjustment for baseline covariates), the changes in A1c and weight were similar for glargine and detemir: -1.4 versus $-1.4 \%$ (Fig. $1 \mathrm{~A}$ ) and +2.5 versus $+1.7 \mathrm{~kg}$ (Fig. 1B), respectively. There were no important differences seen when comparing these variables between the two treatment groups (see Supplementary Appendix 2). Similarly, there was no relevant difference in the $\mathrm{A} 1 \mathrm{c} /$ weight ratio for the glargine versus detemir groups at $1.8 \mathrm{~kg} / \%$ versus $1.2 \mathrm{~kg} / \%$ (Fig. 1C), respectively.

\section{Change in insulin dose per $1 \%$ A1c reduction}

Using the unadjusted results, individuals required a higher detemir dose (36.1 U/day) compared with those receiving glargine $(27.2 \mathrm{U} /$ day) in order to decrease A1c by $1 \%$ (difference, $-8.84 ; 95 \%$ CI $,-17.7,0.03 \mathrm{U} /$ day [see Supplementary Appendix 2]).

In our pooled analysis, the final insulin doses were lower with glargine than with detemir (38.8 vs. $51.5 \mathrm{U} /$ day; difference, $-12.75 ; 95 \% \mathrm{CI},-25.72,-0.21 \mathrm{U} /$ day). The final mean $( \pm \mathrm{SE})$ insulin dose per $\mathrm{kg}$ for glargine and detemir was 0.45 (0.02) and $0.59(0.07) \mathrm{U} / \mathrm{kg}$, respectively.

\section{Discussion}

In the 22 studies identified for this review, the introduction of glargine or detemir to individuals with T2DM inadequately controlled by OADs was associated with a similar reduction in A1c levels of $1.4 \%$. Both treatments were also associated with a modest increase in weight that was within the expected range (increase of $2 \mathrm{~kg}$ per $1 \%$ reduction in A1c). ${ }^{45}$ Furthermore, our analysis shows that weight change with glargine therapy is borderline statistically significantly greater than that with detemir $(P=0.049)$. There was no difference between the treatments per $1 \%$ reduction in A1c levels. A previous meta-analysis ${ }^{15}$ has reported significantly less weight gain with detemir than glargine, where the analysis was restricted to only one study of detemir and four glargine trials, all of which are included in the present analysis. ${ }^{15}$

Our analysis demonstrates that individuals treated with detemir require a higher dose of insulin compared with individuals treated with glargine in order to achieve the same improvement in glycemic control. In the study by Rosenstock et al., ${ }^{2} 55 \%$ of the individuals required twice-daily dosing with detemir by the end of the 52-week treatment period. Twice-daily dosing was associated with a higher overall daily insulin dose and greater weight gain compared with oncedaily dosing. Johnson and Shimshi, ${ }^{46}$ in their recent metaanalysis of seven randomized clinical trials comparing detemir with other basal insulins, demonstrated that the mean total daily insulin dose was greater for detemir than other basal insulins.

When the analysis was conducted using only those studies that included individuals without a history of previous insulin use (the majority of the studies), the results were very similar, except that the limit of the $95 \%$ CI of weight gain difference was borderline in favor of detemir. The final insulin dose for detemir was higher (i.e., twice the dose for glargine) in order to achieve the same levels of glycemic control with glargine.

Caution should be taken, however, when interpreting results from the current analysis, as direct comparison is limited owing to the small number of detemir studies. However, the results are in agreement with other data indicating that weight change with detemir is dose-dependent, ${ }^{2}$ as it is for other insulins. Moreover, in order to help reach glycemic 


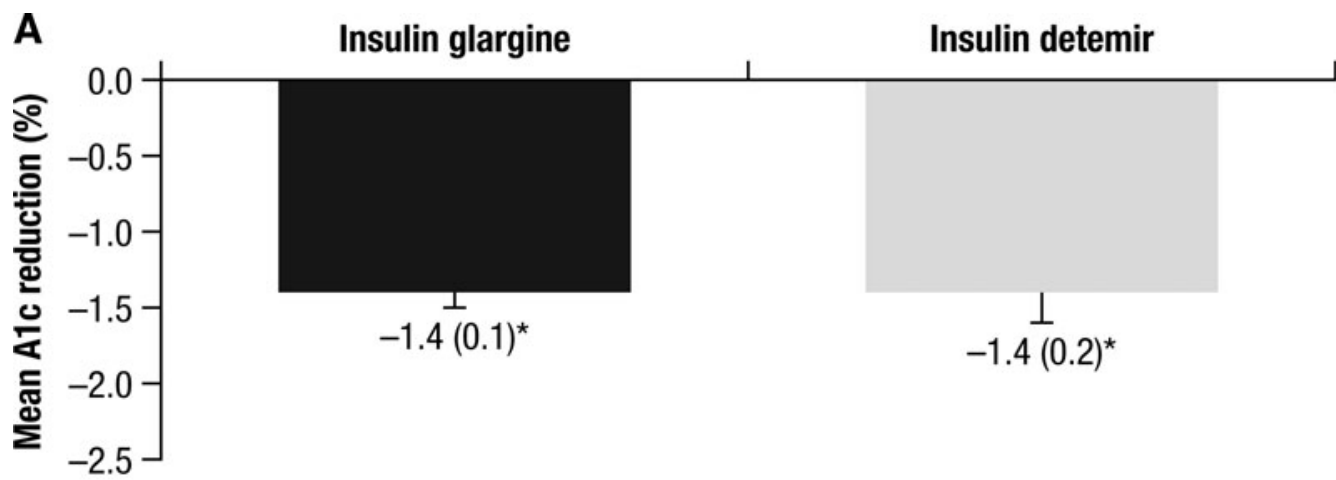

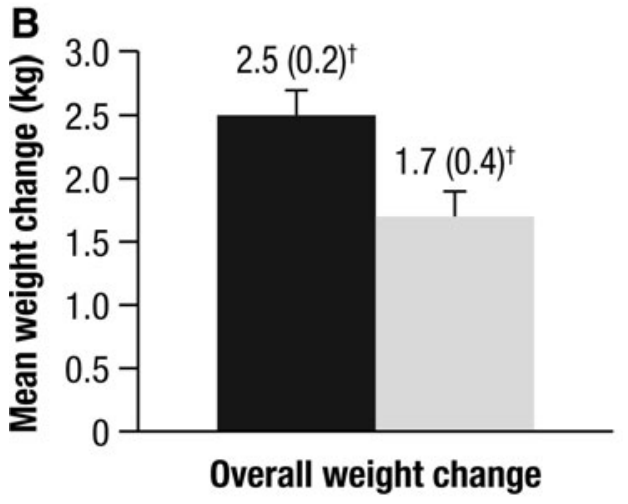

Insulin glargine

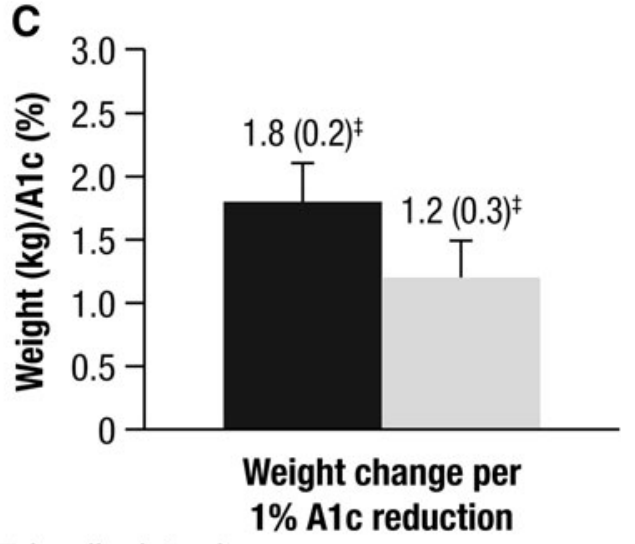

Insulin detemir

FIG. 1. Changes in (A) hemoglobin A1C, (B) weight, and (C) A1c/weight ratio for insulin glargine and insulin detemir. *95\% confidence interval of difference $-0.34,0.38 ;{ }^{\dagger} 95 \%$ confidence interval of difference $0,1.66 ;$ difference $-0.08,1.29$.

targets, many individuals need to inject detemir twice daily, thus necessitating an increase in the frequency of administration and dosage. . $^{7}$

The direct comparison of glargine and detemir data also supposed that the estimators obtained for each product are close to the data that would be obtained in real life conditions. It was not possible to adjust on a potential effect that could interfere with this difference estimation, as only a metaanalysis of only randomized head-to-head studies could address this issue.

The low numbers of detemir studies compared with the glargine studies did not allow testing for covariates such as hypoglycemia and fasting blood glucose. There is also only one study directly comparing detemir and glargine ${ }^{2}$ and no studies comparing once- versus twice-daily regimens of either insulin. However, the results from our analyses are reassuring in that the weight gain was within the expected range per $1 \%$ reduction in A1c for both insulin preparations. Our pooled analysis indicates that weight changes, when adjusted for $1 \%$ reduction in $\mathrm{A} 1 \mathrm{c}$, are consistent with the $4 \mathrm{~T}$ Trial; in this study, basal insulin (detemir), not sufficient for all individuals in terms of A1c change, was associated with significantly less weight gain than the other two regimens that also contained rapid-acting insulin. ${ }^{43}$

This analysis did not adjust for baseline covariates, as this was only possible for the glargine studies, with the small number of studies with detemir precluding adjustment. Therefore, to provide a similar assessment, we have only presented unadjusted data here. However, even with adjustment for baseline covariates for the glargine studies, the pattern of results did not differ. In addition, patient-level data were not available for the studies used in the analysis, and therefore the analysis was carried out with the data as reported in the published studies.

Hypoglycemia is often a limiting factor of insulin therapy and may limit the magnitude of A1c change ${ }^{13}$; similarly, the presence of other adverse events may result in inadequate dose titration and limit A1c change. However, in this analysis, we did not adjust for the effect of rates of hypoglycemia on an individual patient basis (only proportion of patients experiencing hypoglycemia was included in the model) or examine the association between hypoglycemia and change in weight or A1c over the course of the treatment. Although these were considered, the methods of reporting the incidence of hypoglycemia on an individual basis varied greatly between trials, and a meaningful analysis of the effect of hypoglycemia on the change in weight over the course of the treatment was not possible.

Nevertheless, concerns regarding changes in weight are still a major barrier for both individuals with diabetes starting insulin therapy and their caregivers, leading to reduced adherence to insulin regimens and inadequate titration. ${ }^{7,9} \mathrm{Im}$ plementation of effective education programs, including diet and exercise management and self-monitoring of blood glucose, in addition to pharmacotherapy for individuals with $\mathrm{T} 2 \mathrm{DM}$ is a vital element of addressing this barrier. 


\section{Conclusions}

The evidence from the individual studies included in this review and the pooled analysis presented confirm that the use of glargine once daily or detemir once or twice daily as required was associated with relatively low weight gain. Our pooled analysis suggests that although the absolute weight gain was numerically higher with glargine versus detemir, the weight gain with glargine does not differ from detemir when adjusted for the reduction in A1c. Individuals treated with detemir, however, required a higher daily dose of insulin compared with the individuals treated with glargine in order to achieve the same A1c reduction. Therefore, at equipotent dose, the weight gain was not significantly different between the two basal insulin preparations glargine and detemir.

\section{Acknowledgments}

Editorial support for this review was provided by the Global Publications Group of sanofi-aventis.

\section{Author Disclosure Statement}

G.D. has received research grants and speaker's honoraria and served as an occasional consultant for sanofi-aventis. K.A. is an employee of sanofi-aventis. F.M. has received honoraria for statistical analyses conducted for sanofi-aventis. D.O. has received research support and honoraria for consultancy and lecture fees from and has served on the clinical advisory board and as a consultant for sanofi-aventis.

\section{References}

1. Mäkimattila S, Nikkilä K, Yki-Järvinen $\mathrm{H}$ : Causes of weight gain during insulin therapy with and without metformin in patients with Type II diabetes mellitus. Diabetologia 1999; 42:406-412.

2. Rosenstock J, Davies M, Home PD, Larsen J, Koenen C, Schernthaner G: A randomised, 52-week, treat-to-target trial comparing insulin detemir with insulin glargine when administered as add-on to glucose-lowering drugs in insulinnaive people with type 2 diabetes. Diabetologia 2008;51: 408-416.

3. Monnier L, Colette C: Contributions of fasting and postprandial glucose to hemoglobin A1c. Endocr Pract 2006; 12(Suppl 1):42-46.

4. Russell-Jones D, Khan R: Insulin-associated weight gain in diabetes-causes, effects and coping strategies. Diabetes Obes Metab 2007;9:799-812.

5. Davies M, Khunti K: Insulin management in overweight or obese type 2 diabetes patients: the role of insulin glargine. Diabetes Obes Metab 2008;10(Suppl 2):42-49.

6. Hummel J, Kuhner C, Kopf D, Krumm B, Deuschle M, Lederbogen F: Psychosocial barriers to starting insulin therapy in type 2 diabetes mellitus. Diabetes Res Clin Pract 2008;82: e25-e26.

7. Davies M: The reality of glycaemic control in insulin treated diabetes: defining the clinical challenges. Int J Obes Relat Metab Disord 2004;28(Suppl 2):S14-S22.

8. Korytkowski M: When oral agents fail: practical barriers to starting insulin. Int J Obes Relat Metab Disord 2002;26(Suppl 3):S18-S24.

9. Polonsky WH, Fisher L, Guzman S, Villa-Caballero L, Edelman SV: Psychological insulin resistance in patients with type 2 diabetes: the scope of the problem. Diabetes Care 2005;28:2543-2545.

10. Carver C: Insulin treatment and the problem of weight gain in type 2 diabetes. Diabetes Educ 2006;32:910-917.

11. Yki-Järvinen H, Ryysy L, Kauppila M, Kujansuu E, Lahti J, Marjanen T, Niskanen L, Rajala S, Salo S, Seppälä P, Tulokas T, Viikari J, Taskinen MR: Effect of obesity on the response to insulin therapy in noninsulin-dependent diabetes mellitus. J Clin Endocrinol Metab 1997;82:4037-4043.

12. Landstedt-Hallin L, Adamson U, Arner P, Bolinder J, Lins PE: Comparison of bedtime NPH or preprandial regular insulin combined with glibenclamide in secondary sulfonylurea failure. Diabetes Care 1995;18:1183-1186.

13. Mullins P, Sharplin P, Yki-Järvinen H, Riddle MC, Haring HU: Negative binomial meta-regression analysis of combined glycosylated hemoglobin and hypoglycemia outcomes across eleven Phase III and IV studies of insulin glargine compared with neutral protamine Hagedorn insulin in type 1 and type 2 diabetes mellitus. Clin Ther 2007;29:1607-1619.

14. Hermansen K, Davies M, Derezinski T, Martinez Ravn G, Clauson P, Home P: A 26-week, randomized, parallel, treatto-target trial comparing insulin detemir with $\mathrm{NPH}$ insulin as add-on therapy to oral glucose-lowering drugs in insulinnaive people with type 2 diabetes. Diabetes Care 2006;29: 1269-1274.

15. Fakhoury W, Lockhart I, Kotchie RW, Aagren M, LeReun C: Indirect comparison of once daily insulin detemir and glargine in reducing weight gain and hypoglycaemic episodes when administered in addition to conventional oral antidiabetic therapy in patients with type-2 diabetes. Pharmacology 2008;82:156-163.

16. Vague P, Selam JL, Skeie S, De Leeuw I, Elte JW, Haahr H, Kristensen A, Draeger E: Insulin detemir is associated with more predictable glycemic control and reduced risk of hypoglycemia than NPH insulin in patients with type 1 diabetes on a basal-bolus regimen with premeal insulin aspart. Diabetes Care 2003;26:590-596.

17. De Leeuw I, Vague P, Selam JL, Skeie S, Lang H, Draeger E, Elte JW: Insulin detemir used in basal-bolus therapy in people with type 1 diabetes is associated with a lower risk of nocturnal hypoglycaemia and less weight gain over 12 months in comparison to NPH insulin. Diabetes Obes Metab 2005;7:73-82.

18. Standl E, Lang H, Roberts A: The 12-month efficacy and safety of insulin detemir and NPH insulin in basal-bolus therapy for the treatment of type 1 diabetes. Diabetes Technol Ther 2004;6:579-588.

19. Russell-Jones D, Simpson R, Hylleberg B, Draeger E, Bolinder J: Effects of QD insulin detemir or neutral protamine Hagedorn on blood glucose control in patients with type I diabetes mellitus using a basal-bolus regimen. Clin Ther 2004;26:724-736.

20. Pieber TR, Draeger E, Kristensen A, Grill V: Comparison of three multiple injection regimens for Type 1 diabetes: morning plus dinner or bedtime administration of insulin detemir vs. morning plus bedtime NPH insulin. Diabet Med 2005;22:850-857.

21. Hermansen K, Fontaine P, Kukolja KK, Peterkova V, Leth G, Gall MA: Insulin analogues (insulin detemir and insulin aspart) versus traditional human insulins (NPH insulin and regular human insulin) in basal-bolus therapy for patients with type 1 diabetes. Diabetologia 2004;47:622-629.

22. Home $\mathrm{P}$, Bartley $\mathrm{P}$, Russell-Jones $\mathrm{D}$, Hanaire-Broutin $\mathrm{H}$, Heeg JE, Abrams P, Landin-Olsson M, Hylleberg B, Lang H, 
Draeger E: Insulin detemir offers improved glycemic control compared with NPH insulin in people with type 1 diabetes: a randomized clinical trial. Diabetes Care 2004;27:1081-1087.

23. Haak T, Tiengo A, Draeger E, Suntum M, Waldhausl W: Lower within-subject variability of fasting blood glucose and reduced weight gain with insulin detemir compared to $\mathrm{NPH}$ insulin in patients with type 2 diabetes. Diabetes Obes Metab 2005;7:56-64.

24. Raslova K, Bogoev M, Raz I, Leth G, Gall MA, Hancu N: Insulin detemir and insulin aspart: a promising basal-bolus regimen for type 2 diabetes. Diabetes Res Clin Pract 2004;66: 193-201.

25. Bretzel RG, Nuber U, Landgraf W, Owens DR, Bradley C, Linn T: Once-daily basal insulin glargine versus thrice-daily prandial insulin lispro in people with type 2 diabetes on oral hypoglycaemic agents (APOLLO): an open randomised controlled trial. Lancet 2008;371:1073-1084.

26. Eliaschewitz FG, Calvo C, Valbuena H, Ruiz M, Aschner P, Villena J, Ramirez LA, Jimenez J: Therapy in type 2 diabetes: insulin glargine vs. NPH insulin both in combination with glimepiride. Arch Med Res 2006;37:495-501.

27. Fritsche A, Schweitzer MA, Haring HU: Glimepiride combined with morning insulin glargine, bedtime neutral protamine Hagedorn insulin, or bedtime insulin glargine in patients with type 2 diabetes. A randomized, controlled trial. Ann Intern Med 2003;138:952-959.

28. Gerstein HC, Yale JF, Harris SB, Issa M, Stewart JA, Dempsey E: A randomized trial of adding insulin glargine vs. avoidance of insulin in people with Type 2 diabetes on either no oral glucose-lowering agents or submaximal doses of metformin and/or sulphonylureas. The Canadian INSIGHT (Implementing New Strategies with Insulin Glargine for Hyperglycaemia Treatment) Study. Diabet Med 2006; 23:736-742.

29. Heine RJ, Van Gaal LF, Johns D, Mihm MJ, Widel MH, Brodows RG: Exenatide versus insulin glargine in patients with suboptimally controlled type 2 diabetes: a randomized trial. Ann Intern Med 2005;143:559-569.

30. Janka HU, Plewe G, Riddle MC, Kliebe-Frisch C, Schweitzer MA, Yki-Järvinen H: Comparison of basal insulin added to oral agents versus twice-daily premixed insulin as initial insulin therapy for type 2 diabetes. Diabetes Care 2005;28: 254-259.

31. Kann PH, Wascher T, Zackova V, Moeller J, Medding J, Szocs A, Mokan M, Mrevlje F, Regulski M: Starting insulin therapy in type 2 diabetes: twice-daily biphasic insulin Aspart 30 plus metformin versus once-daily insulin glargine plus glimepiride. Exp Clin Endocrinol Diabetes 2006;114: 527-532.

32. Kazda C, Hulstrunk H, Helsberg K, Langer F, Forst T, Hanefeld M: Prandial insulin substitution with insulin lispro or insulin lispro mid mixture vs. basal therapy with insulin glargine: a randomized controlled trial in patients with type 2 diabetes beginning insulin therapy. J Diabetes Complications 2006;20:145-152.

33. Pan CY, Sinnassamy P, Chung KD, Kim KW: Insulin glargine versus NPH insulin therapy in Asian Type 2 diabetes patients. Diabetes Res Clin Pract 2007;76:111-118.

34. Raskin P, Allen E, Hollander P, Lewin A, Gabbay RA, Hu P, Bode B, Garber A: Initiating insulin therapy in type 2 diabetes: a comparison of biphasic and basal insulin analogs. Diabetes Care 2005;28:260-265.
35. Riddle MC, Rosenstock J, Gerich J: The treat-to-target trial: randomized addition of glargine or human NPH insulin to oral therapy of type 2 diabetic patients. Diabetes Care 2003; 26:3080-3086.

36. Rosenstock J, Sugimoto D, Strange P, Stewart JA, Soltes-Rak E, Dailey G: Triple therapy in type 2 diabetes: insulin glargine or rosiglitazone added to combination therapy of sulfonylurea plus metformin in insulin-naive patients. Diabetes Care 2006;29:554-559.

37. Standl E, Maxeiner S, Raptis S: Once-daily insulin glargine administration in the morning compared to bedtime in combination with morning glimepiride in patients with type 2 diabetes: an assessment of treatment flexibility. Horm Metab Res 2006;38:172-177.

38. Yki-Järvinen $H$, Dressler A, Ziemen M: Less nocturnal hypoglycemia and better post-dinner glucose control with bedtime insulin glargine compared with bedtime NPH insulin during insulin combination therapy in type 2 diabetes. HOE 901/3002 Study Group. Diabetes Care 2000;23:1130-1136.

39. Yki-Järvinen $H$, Juurinen $L$, Alvarsson $M$, Bystedt $T$, Caldwell I, Davies M, Lahdenperä S, Nijpels G, Vähätalo M: Initiate Insulin by Aggressive Titration and Education (INITIATE): a randomized study to compare initiation of insulin combination therapy in type 2 diabetic patients individually and in groups. Diabetes Care 2007;30:1364-1369.

40. Yki-Järvinen $\mathrm{H}$, Kauppinen-Mäkelin $\mathrm{R}$, Tiikkainen $\mathrm{M}$, Vähätalo M, Virtamo H, Nikkilä K, Tulokas T, Hulme S, Hardy K, McNulty S, Hänninen J, Levänen H, Lahdenperä S, Lehtonen R, Ryysy L: Insulin glargine or NPH combined with metformin in type 2 diabetes: the LANMET study. Diabetologia 2006;49:442-451.

41. Yokoyama H, Tada J, Kamikawa F, Kanno S, Yokota Y, Kuramitsu M: Efficacy of conversion from bedtime $\mathrm{NPH}$ insulin to morning insulin glargine in type 2 diabetic patients on basal-prandial insulin therapy. Diabetes Res Clin Pract 2006;73:35-40.

42. Philis-Tsimikas A, Charpentier G, Clauson P, Ravn GM, Roberts VL, Thorsteinsson B: Comparison of once-daily insulin detemir with NPH insulin added to a regimen of oral antidiabetic drugs in poorly controlled type 2 diabetes. Clin Ther 2006;28:1569-1581.

43. Holman RR, Thorne KI, Farmer AJ, Davies MJ, Keenan JF, Paul S, Levy JC: Addition of biphasic, prandial, or basal insulin to oral therapy in type 2 diabetes. N Engl J Med 2007; 357:1716-1730.

44. Raskin P: Initiation of insulin therapy in patients with type 2 diabetes failing oral therapy: response to Mikhail and Cope and to Janka. Diabetes Care 2005;28:2811.

45. Yki-Järvinen $\mathrm{H}$ : Combination therapies with insulin in type 2 diabetes. Diabetes Care 2001;24:758-767.

46. Johnson C, Shimshi M: When a unit of insulin is not a unit: detemir dosing and insulin cost in type 2 diabetes mellitus. Insulin 2009;4:87-93.

Address correspondence to: George Dailey, M.D.

Department of Diabetes and Endocrinology Scripps Clinic Torrey Pines 10666 North Torrey Pines Road La Jolla, CA 92037

E-mail: Dailey.George@scrippshealth.org 
